\title{
Dolomitic lime: thermal decomposition of nesquehonite
}

J. Lanas, J.I. Alvarez *

Departamento de Química, Universidad de Navarra, 31080 Pamplona, Spain

$\mathbf{N}^{\circ}$ of pages: 26

$\mathbf{N}^{\circ}$ of tables: 1

$\mathbf{N}^{0}$ of figures: 12

Keywords: Nesquehonite, Hydromagnesite, Thermal decomposition, Dolomitic quicklime, Amorphous magnesium carbonate.

Please, send all correspondence to:

Dr. José I. Alvarez Galindo

Dpto. de Química

Fac. de Ciencias

Universidad de Navarra

$\mathrm{C} /$ Irunlarrea s/n

31.080 Pamplona (Navarra)

Spain

Phone: 34948425600

Fax: 34948425649

E-mail: jalvarez@unav.es 


\title{
Dolomitic lime: thermal decomposition of nesquehonite
}

\author{
J. Lanas, J.I. Alvarez * \\ ${ }^{a}$ Departamento de Química, Universidad de Navarra, 31080 Pamplona, Spain
}

\section{ABSTRACT:}

Nesquehonite $\left(\mathrm{MgCO}_{3} \cdot 3 \mathrm{H}_{2} \mathrm{O}\right)(\mathrm{N})$ can be obtained from a dolomitic quicklime paste in a $\mathrm{CO}_{2}$-rich atmosphere. Thermal decomposition of this synthetic nesquehonite has been studied by TG-DTA analysis. It is very similar to the hydromagnesite (HY) thermal decomposition, as it show similarities in the decarbonations at 440 and $550^{\circ} \mathrm{C}$, and an exothermic phenomenon at $510^{\circ} \mathrm{C}$.

It has been reported in the literature that some intermediate in $\mathrm{N} \rightarrow \mathrm{HY}$ transformation occur, but this process can not be directly detected during the heating. Samples were heated at 115, 230, 280, 370, 460, 520, 600, 800 and $1000^{\circ} \mathrm{C}$ and XRD and FT-IR were used in order to determine the structural changes in nesquehonite and the intermediate phases formed.

Results show that nesquehonite transforms at lower temperatures $\left(115^{\circ} \mathrm{C}\right)$ into a stable amorphous magnesium carbonate with chemical composition very close to that of HY. Thermal decomposition of nesquehonite, during a gradual temperature increase, proceeds via the formation of this compound. At higher temperatures $\left(460^{\circ} \mathrm{C} / \mathrm{short}\right.$ heating times), nesquehonite transforms into HY.

The occurrence of an exothermic peak at $510^{\circ} \mathrm{C}$ has been also discussed.

Keywords: Nesquehonite, Hydromagnesite, Thermal decomposition, Dolomitic quicklime, Amorphous magnesium carbonate. 


\section{Dolomitic lime: thermal decomposition of the nesquehonite obtained}

\section{Introduction}

As stated in our previous work [1], dolomitic lime-based pastes involved the $\mathrm{CaO}$ $\mathrm{MgO}-\mathrm{H}_{2} \mathrm{O}-\mathrm{CO}_{2}$ system, and there are wide possibilities for the formation of different compounds. In the aforementioned work, pastes made with a dolomitic quicklime (DQ) were prepared and studied in order to establish the new phases formed after the carbonation process. In a $\mathrm{CO}_{2}$-rich environment, DQ pastes produced nesquehonite $\left(\mathrm{MgCO}_{3} \cdot 3 \mathrm{H}_{2} \mathrm{O}\right)(\mathrm{N})$ as result of $\mathrm{Mg}(\mathrm{OH})_{2}$ carbonation.

Nesquehonite precipitates from solutions of magnesium bicarbonate below $52^{\circ} \mathrm{C}$, while hydromagnesite $\left(\mathrm{Mg}_{5}\left(\mathrm{CO}_{3}\right)_{4}(\mathrm{OH})_{2} \cdot 4 \mathrm{H}_{2} \mathrm{O}\right)(\mathrm{HY})$ turns out to be the stable hydrate above this temperature [2].

A great number of magnesium carbonates with very close chemical composition can be obtained from the $\mathrm{MgO}-\mathrm{CO}_{2}-\mathrm{H}_{2} \mathrm{O}$ system, as has been reported [3]. Furthermore, several unidentified magnesium carbonates have been detected, some of them with amorphous structures [4-6].

With regard to nesquehonite, Davies and Bubela [2] study its transformation into hydromagnesite through an intermediate phase structurally similar to dypingite. Botha and Strydom [4] obtain an unidentified structure, which shows similarities with hydromagnesite and appears to be an intermediate phase between nesquehonite and hydromagnesite. However, heating nesquehonite at 80,100 and $120^{\circ} \mathrm{C}$, the authors only obtain the unidentified product but no the conversion to hydromagnesite, as expected. Thermal decomposition of nesquehonite poses some gaps in the literature: Sawada and co-workers [7] give some information about it. The occurrence of an exothermic phenomenon at $\sim 500^{\circ} \mathrm{C}$ is not explained [2,8]; in other papers this phenomenon was not 
observed at all [4,5]. Kloprogge et al. [9] characterized a nesquehonite obtained at low temperature, but no thermal techniques were used.

Therefore, the aim of this work is to study the thermal decomposition of synthetic nesquehonite obtained in dolomitic lime-based pastes, by TG-DTA analysis. XRD and FT-IR have been used in order to determine the intermediate phases. The attributions of the endothermic peaks and the occurrence of the exothermic phenomenon at $\sim 500^{\circ} \mathrm{C}$ are also discussed. As has been determined, thermal decomposition of nesquehonite proceeds via an amorphous structure very similar to hydromagnesite.

\section{Experimental Work}

\subsection{Nesquehonite preparation}

By slaking a dolomitic quicklime (DQ) made up of $\mathrm{CaO}$ and $\mathrm{MgO}$ (Fig. 1(a)) in a $\mathrm{CO}_{2}$ environment, a lime paste with nesquehonite and calcite as the main constituents (Fig. 1(b)) was obtained. This slaking process was conducted in a glass reactor of $2 \mathrm{~L}$, with continuous stirring (Heidolph Stierrer RZR 2021 at $~ 350 \mathrm{rpm}$ of speed) and a continuous $\mathrm{CO}_{2}$ flow $\left(2 \mathrm{~L} \cdot \mathrm{min}^{-1}\right)$ [1]. Although the nesquehonite and calcite were formed in two hours, this slaking process was carried out for 4 hours to ensure the complete transformation of the compounds in their corresponding carbonates. The mortar paste obtained was conserved in a desiccator until its heating at the different temperatures.

\subsection{Thermal treatment}

The obtained paste was heated at different temperatures and times. A P. SELECTA Digitheat-80L heater was used for the lowest temperature $\left(115^{\circ} \mathrm{C}\right)$ and a CARBOLITE ELF 11/14 furnace for the higher ones (230, 280, 370, 460, 520, 600, 800 and $1000^{\circ} \mathrm{C}$ ). 


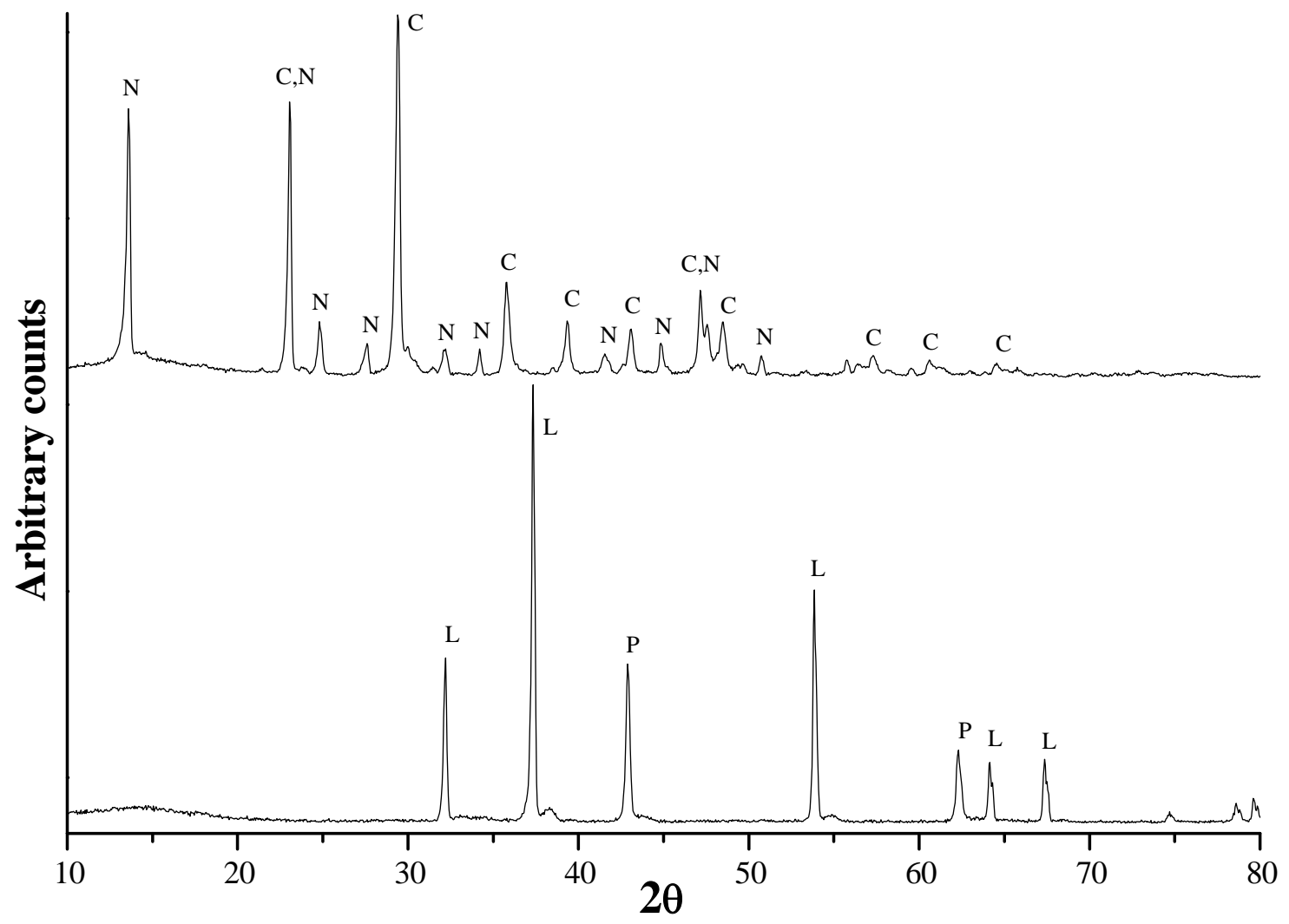

Fig. 1. XRD. (a) DQ lime; (b) carbonated lime paste. (C: Calcite $\left(\mathrm{CaCO}_{3}\right)$ (ICDD 05-0586); P: Periclase (MgO) (ICDD 45-0946); L: Lime (CaO) (ICDD 37-1497); N: Nesquehonite $\left(\mathrm{MgCO}_{3} \cdot 3 \mathrm{H}_{2} \mathrm{O}\right)$ (ICDD 200669)).

\subsection{Hydromagnesite}

Hydromagnesite used as standard was $\mathrm{Mg}_{5}\left(\mathrm{CO}_{3}\right)_{4}(\mathrm{OH})_{2} \cdot 4 \mathrm{H}_{2} \mathrm{O}$, a hydrated magnesium carbonate hydroxide obtained from Merck an indicated as PA Merck Ref. 5827.

\subsection{Analytical methodology}

\subsubsection{Mineralogical analysis}

In order to determine the mineralogical components contained in the samples and the occurrence of new phases formed at the different temperatures of heating, the different samples were studied by XRD. These analyses were carried out using a Bruker D8 Advance diffractometer (Karlsruhe, Germany), according to the diffraction powder 
method, with a CuK $\alpha 1$ radiation and $0.05^{\circ} 2 \theta$ increments at a rate of $0.05 \mathrm{~s} \cdot \mathrm{step}^{-1}$, scanned from $10^{\circ}$ to $80^{\circ} 2 \theta$. The results were compared with the ICDD database.

\subsubsection{Thermal analysis}

Differential thermal and thermogravimetric analysis (DTA-TG) were conducted at the different temperatures of treatment using a simultaneous TGA-sDTA 851 Mettler Toledo thermoanalyser (Schwerzenbach, Switzerland) with alumina crucibles, fitted with holed lids, at a $20^{\circ} \mathrm{C} \min ^{-1}$ heating rate, under static air atmosphere, from ambient temperature to $1200^{\circ} \mathrm{C}$.

When it was necessary the experimental conditions were changed: a dynamic $\mathrm{CO}_{2}$ flow of $150 \mathrm{~mL} \cdot \mathrm{min}^{-1}$ was employed and/or crucibles without lids were also used.

\subsubsection{Infrared spectroscopy}

All the samples were analyzed by FT-IR spectroscopy, using $\mathrm{KBr}$ pellet. The analysis was performed with a Nicolet-FTIR Avatar 360, with OMNIC E.S.P. software. The resolution was $2 \mathrm{~cm}^{-1}$ and the spectra were the result of averaging 100 scans. All measurements were carried out on powder samples at $20 \pm 1^{\circ} \mathrm{C}$ and ca. $40 \% \mathrm{RH}$.

\section{Results and discussion}

\subsection{TG-DTA results}

As discussed in some previous reports, nesquehonite has been obtained by $\mathrm{Mg}(\mathrm{OH})_{2}$ carbonation, because it is the kinetically favored phase, whereas dolomite, magnesite, artinite, or hydromagnesite are kinetically inhibited [1,3]. The obtaining temperature $\left(\sim 20^{\circ} \mathrm{C}\right)$ at which it was obtained, is in agreement with the highest stability of $\mathrm{N}$ below $55^{\circ} \mathrm{C}[2]$. 
Fig. 2 represents DTA-TG curves of the carbonated lime paste with the obtained N. At around $\sim 200^{\circ} \mathrm{C}$ a marked endothermic peak with associated weight loss can be observed. In literature this phenomenon was attributed to the loss of two water molecules of the $\mathrm{N}$ [8]. Another endothermic peak is also detected at $440^{\circ} \mathrm{C}$, with associated weight loss. In the work by Webb [8] this peak is related to the loss of the remaining water molecule of the nesquehonite, whereas Sawada and co-workers [7] state that only dehydration proceeds up to $\sim 300^{\circ} \mathrm{C}$, and the decarbonation takes place above this temperature.

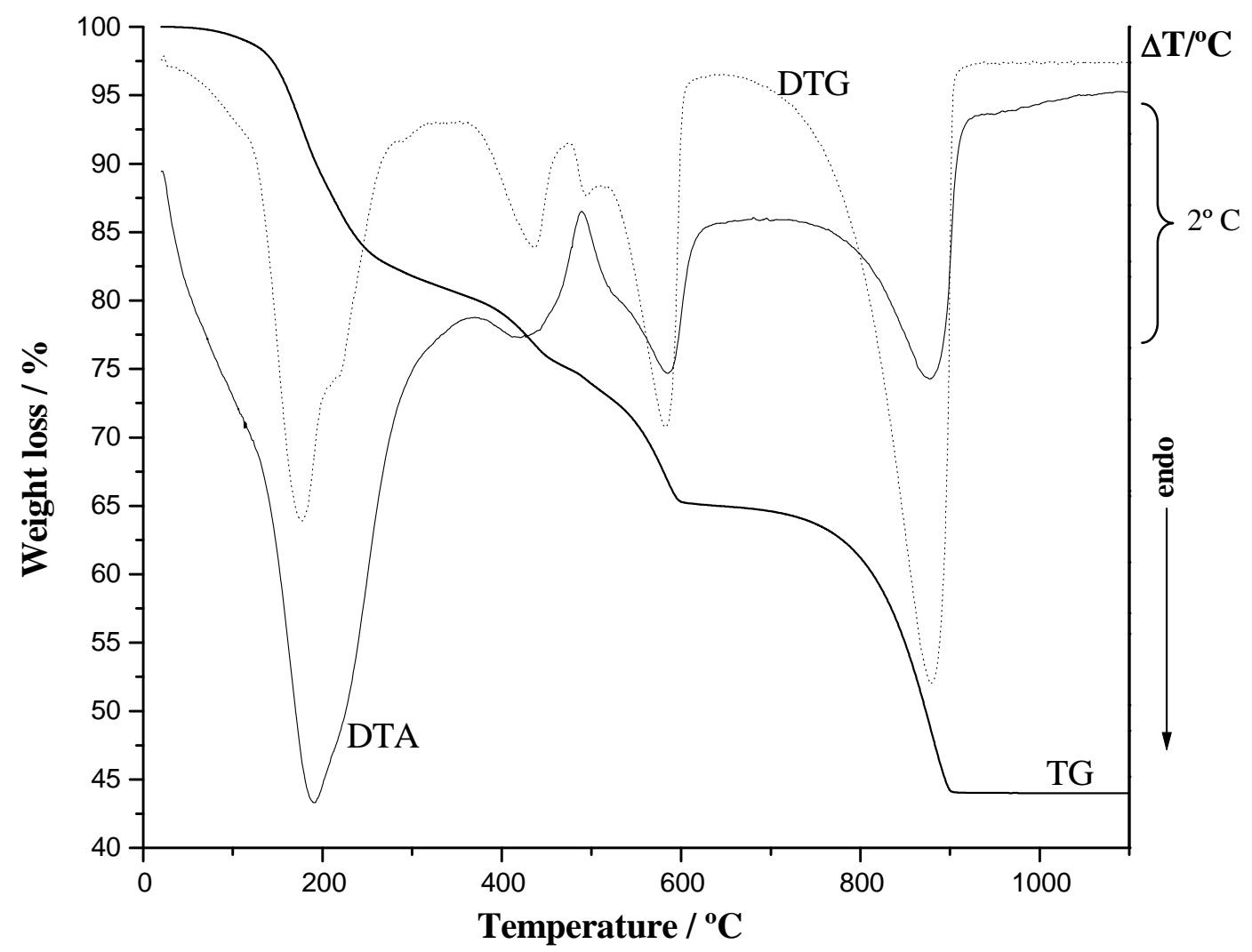

Fig. 2. TG, DTG and DTA curves of the carbonated lime paste (nesquehonite + calcite).

At $\sim 510^{\circ} \mathrm{C}$, a sharp exothermic peak can be observed in the DTA curve. This peak is accompanied by a pronounced weight loss. As reported in the introduction, this exothermic phenomenon does not occur in the works by Botha and Strydom [4,5] or Brousse and Guering [10], nor has any explanation been given for this peak [2,8]. 
The occurrence of a similar exothermic peak for the HY has been discussed in our previous work [11]. The explanation we provided, together with the discussion in the paper by Sawada et al. [7] is as follows: $\mathrm{MgCO}_{3}$ crystallizes suddenly from the amorphous phase with a sharp exothermic peak and a rapid evolution of carbon dioxide takes place simultaneously, which justifies the sharp weight loss. As later discussed, the experimental conditions appear to be of great importance in the occurrence of the peak. At $\sim 550^{\circ} \mathrm{C}$, decarbonation of $\mathrm{MgCO}_{3}$ takes place, as the endothermic peak (DTA curve) and the weight loss (TG curve) reflect [7].

Finally, due to the raw material (dolomitic lime), nesquehonite has been obtained together with calcite (from $\mathrm{MgO}-\mathrm{CaO}-\mathrm{CO}_{2}-\mathrm{H}_{2} \mathrm{O}$ system), so the endothermic phenomena at $\sim 900^{\circ} \mathrm{C}$ is attributed to calcite decomposition.

Compared to $\mathrm{HY}$, thermal decomposition of $\mathrm{N}$ is very similar to that the $\mathrm{HY}$, especially beyond $350^{\circ} \mathrm{C}$. Fig. 3 shows the thermal decomposition of $\mathrm{HY}$, and the similarities in the decarbonations at $440^{\circ} \mathrm{C}$ and $550^{\circ} \mathrm{C}$, and the exothermic peak at $510^{\circ} \mathrm{C}$ are clearly detectable.

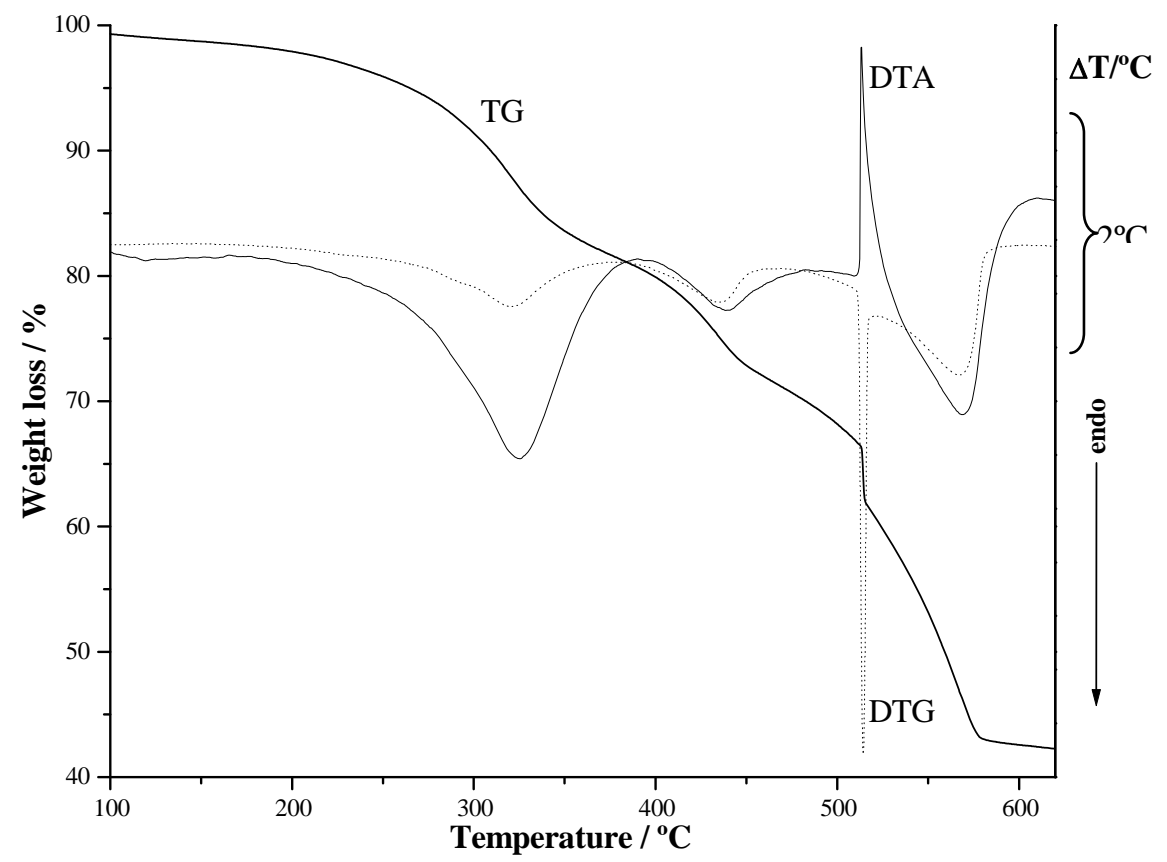

Fig. 3. TG, DTG and DTA curves of the hydromagnesite (HY). 
HY shows an endothermic peak at $\sim 310^{\circ} \mathrm{C}$, which can be attributed to dehydration. A similar endothermic peak has also been reported for natural nesquehonite [2].

Differences can also be observed at $\sim 200^{\circ} \mathrm{C}$, with a marked dehydration in N. Taking into account the chemical compositions for $\mathrm{N}\left(\mathrm{MgCO}_{3} \cdot 3 \mathrm{H}_{2} \mathrm{O}\right)$ and $\mathrm{HY}$ $\left(\mathrm{Mg}_{5}\left(\mathrm{CO}_{3}\right)_{4}(\mathrm{OH})_{2} \cdot 4 \mathrm{H}_{2} \mathrm{O}\right)$, one can deduce mole proportions of 1:1:3 (MgO: $\left.\mathrm{CO}_{2}: \mathrm{H}_{2} \mathrm{O}\right)$ for $\mathrm{N}$ and 1:0.8:1 (MgO: $\mathrm{CO}_{2}: \mathrm{H}_{2} \mathrm{O}$ ) for $\mathrm{HY}$, which show a higher amount of water in $\mathrm{N}$ than in HY.

After the elimination of this excess water, and due to the rather similar thermal curves, one could get the impression that $\mathrm{N}$ is transformed into HY during the heating process. This hypothesis is strengthened by the greater stability of HY at higher temperatures (transformation of $\mathrm{N}$ into $\mathrm{HY}$ at $\mathrm{T}>55^{\circ} \mathrm{C}$ ) [2]. However, the scarce information in the literature and the occurrence of some intermediate in $\mathrm{N} \rightarrow \mathrm{HY}$ transformation necessitated the more detailed study that follows.

\subsection{Thermal treatment}

Samples were heated up to different temperatures (115, 230, 280, 370, 460, 520, 600, 800 and $1000^{\circ} \mathrm{C}$ ) and studied by XRD in order to establish the structural changes in nesquehonite. Then a DTA-TG analysis was also performed. Temperatures were selected as a function of the thermal behavior described for $\mathrm{HY}, \mathrm{N}$ and calcite.

Obviously, structural changes are also related to the heating time: this variable has been taken into account during the heating at different temperatures. The heating time has been increased until a constant diffraction pattern was obtained. It must be stressed that the higher amount of sample resulted in an increase of the heating time in order to obtain the necessary equilibria. 
Fig. 4 shows the XRD results of these heating processes. During prolonged heating at $115^{\circ} \mathrm{C}$, (>>5-6 h), nesquehonite suffered a marked change and lost its crystalline structure. XRD analysis detected the calcite diffraction peaks. Also some peaks (attributed to an unidentified compound, UIC) typical for almost amorphous structures, can be found at 17, 28, 31.5, 32.9 and $35^{\circ} 2 \theta$, which correspond to 5.21, 3.18, 2.84, 2.72 and $2.56 \mathrm{~d}$ values, respectively. These peaks match with the unidentified product obtained by Botha and Strydom [4] under similar conditions. The authors report same similarities between HY and the unidentified product. Although Davies and Bubela [2] describe an intermediate in the $\mathrm{N} \rightarrow \mathrm{HY}$ transformation (protohydromagnesite, similar to dypingite), its X-ray diffraction pattern does not match our results.

In this work, the relative stability of the unidentified compound (UIC) can be proved by its effect of increasing the heating time. DTA-TG results for the sample heated at $115^{\circ} \mathrm{C} / 18 \mathrm{~h}$ are collected in Fig 5 . As can be observed, the thermal behavior of the UIC is very similar to that of $\mathrm{HY}$, except for the water loss at $\sim 200^{\circ} \mathrm{C}$, as seen in the nesquehonite thermal decomposition. DTA-TG curves fits with those reported by Botha and Strydom for the unidentified product [4].

Thermogravimetric calculations have been carried out in order to establish the resemblance between the composition of UIC and other similar compounds. Table 1 summarizes these results. For the treated sample at $115^{\circ} \mathrm{C} / 18 \mathrm{~h}$, the chemical composition of the UIC (experimental results) closely resembles that of the HY. 


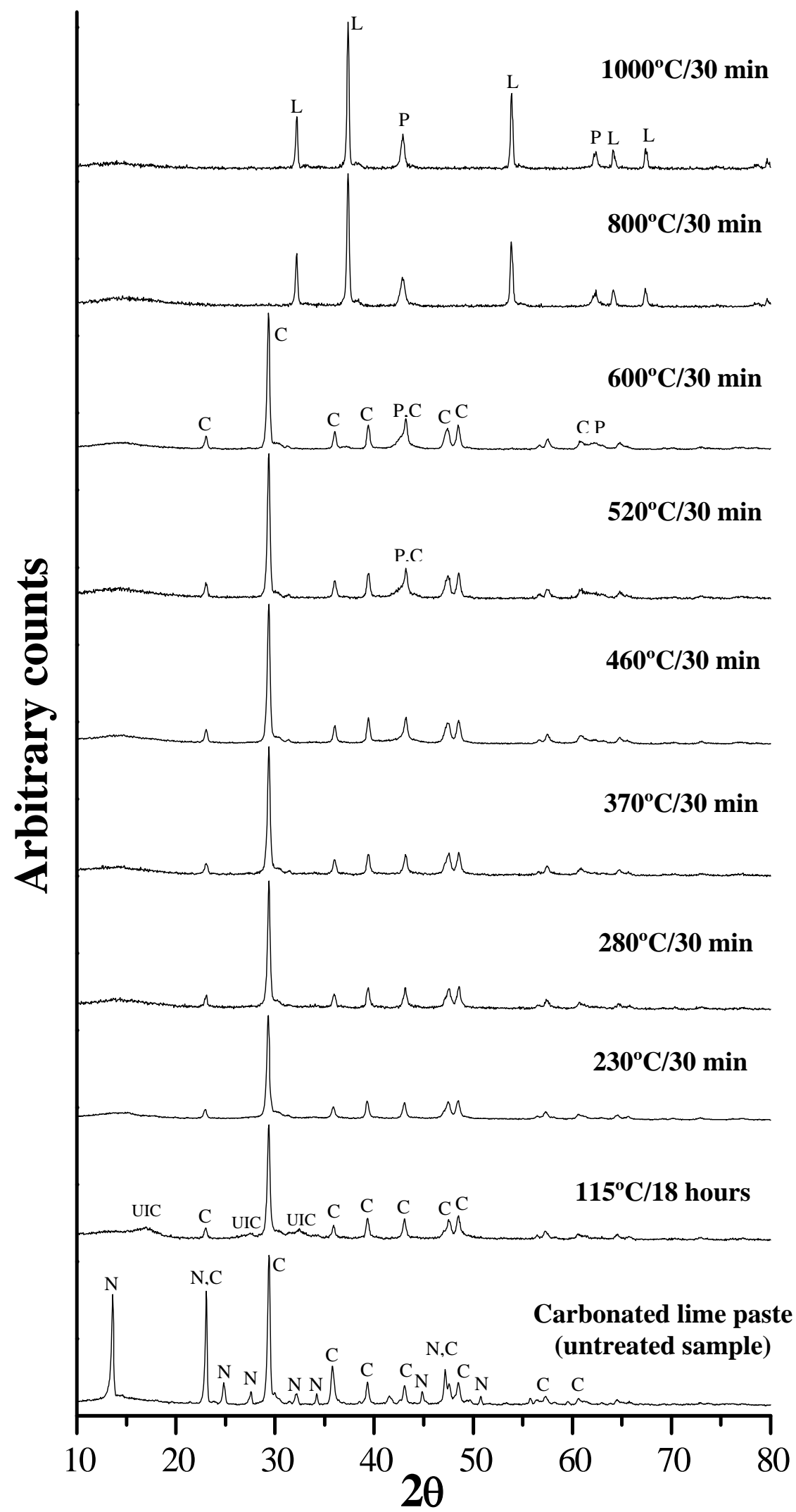

Fig. 4. XRD of the carbonated lime paste evolution as function of the heating temperature. (C: Calcite $\left(\mathrm{CaCO}_{3}\right)$ (ICDD 05-0586); P: Periclase (MgO) (ICDD 45-0946); L: Calcium oxide (CaO) (ICDD 371497); N: Nesquehonite $\left(\mathrm{MgCO}_{3} \cdot 3 \mathrm{H}_{2} \mathrm{O}\right)$ (ICDD 20-0669), UIC: Unidentified Compound). 
Table 1. Thermogravimetric data of experimental results and calculated for some typical magnesium carbonates at different ranges of temperatures as a function of thermal treatment

\section{Range of temperatures}

\begin{tabular}{|c|c|c|c|c|c|}
\hline \multicolumn{3}{|c|}{ Ambient-610 ${ }^{\circ} \mathrm{C}$} & \multicolumn{3}{|c|}{$100-330^{\circ} \mathrm{C}$} \\
\hline $\begin{array}{c}\text { Treated } \\
\text { sample at } \\
115^{\circ} \mathrm{C} / 18 \mathrm{~h}\end{array}$ & $\begin{array}{c}\text { Treated } \\
\text { sample at } \\
230^{\circ} \mathrm{C} / 30 \mathrm{~min}\end{array}$ & $\begin{array}{c}\text { Treated } \\
\text { sample at } \\
370^{\circ} \mathrm{C} / 30 \mathrm{~min}\end{array}$ & $\begin{array}{c}\text { Treated } \\
\text { sample at } \\
115^{\circ} \mathrm{C} / 18 \mathrm{~h}\end{array}$ & $\begin{array}{c}\text { Treated } \\
\text { sample at } \\
230^{\circ} \mathrm{C} / 30 \mathrm{~min}\end{array}$ & $\begin{array}{c}\text { Treated } \\
\text { sample at } \\
370^{\circ} \mathrm{C} / 30 \mathrm{~min}\end{array}$ \\
\hline
\end{tabular}

\begin{tabular}{ccc} 
& $\mathbf{3 3 5 - 6 1 0} \mathbf{C}$ & \\
\hline Treated & Treated & Treated \\
sample at & sample at & sample at \\
$115^{\circ} \mathrm{C} / 18 \mathrm{~h}$ & $230^{\circ} \mathrm{C} / 30 \mathrm{~min}$ & $370^{\circ} \mathrm{C} / 30 \mathrm{~min}$
\end{tabular}

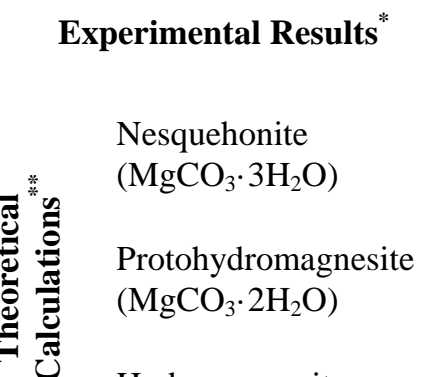

60.30

50.26

41.84

21.84

4.40

$-$

38.47

45.86

41.84

70.86

60.61

52.20

39.05

17.60

$-$

31.81

43.01

52.20

66.50

56.81

52.20

29.93

9.65

$-$

36.58

47.16

52.20

Hydromagnesite $\left(\mathrm{Mg}_{5}\left(\mathrm{CO}_{3}\right)_{4}(\mathrm{OH})_{2} \cdot 4 \mathrm{H}_{2} \mathrm{O}\right)$

56.90

51.03

46.62

19.25

8.26

42.77

46.62

* Weight loss due to the occurrence of calcite has been taken into account in order to correct the experimental values.

${ }^{* *}$ At different temperatures of thermal treatment the weight loss due to the heating process has been considered for theoretical calculations. 


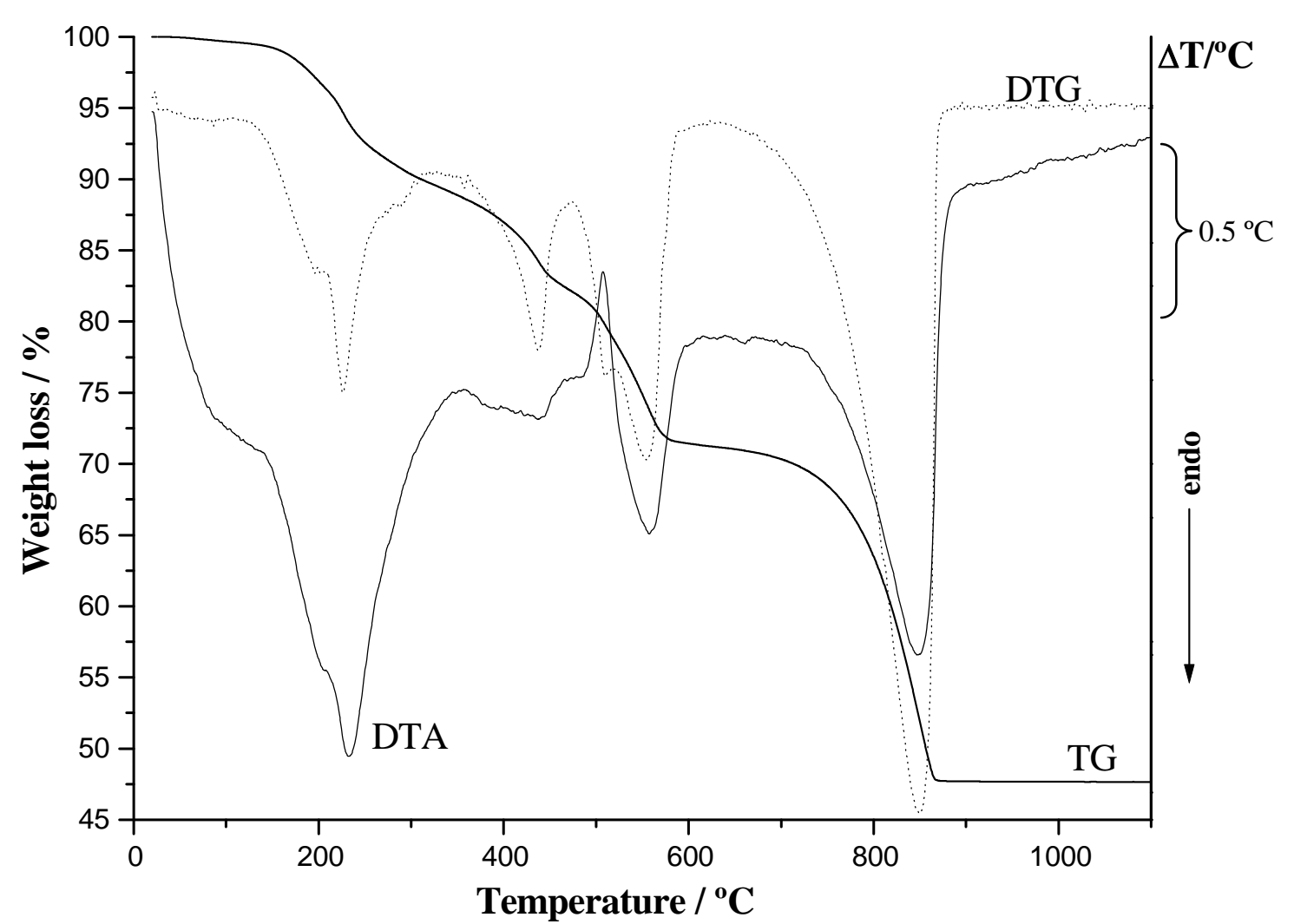

Fig. 5. TG, DTG, and DTA curves of the carbonated lime paste heated at $115^{\circ} \mathrm{C}$ during 18 hours, with the UIC and calcite occurrence.

FT-IR can confirm some similarities between UIC and HY. Nesquehonite in the untreated sample (carbonated lime paste) presents some characteristics absorption bands (Fig. 6). In the region $400-2000 \mathrm{~cm}^{-1}$, the IR spectrum of $\mathrm{N}$ displays $v_{2}$ (bending nonplanar mode) at $850 \mathrm{~cm}^{-1}$. Two strong bands occur around 1466 and $1512 \mathrm{~cm}^{-1}$. The OH-bending mode of water can be ascribed at $1645 \mathrm{~cm}^{-1}$ band. This band is resulting from the presence of a small amount of absorbed water on the surfaces of the nesquehonite crystals [9,12].

On the other hand, $\mathrm{HY}$ shows the $\mathrm{CO}_{3}{ }^{2-} v_{3}$ asymmetric stretching vibrations as a strong band split in two at $\sim 1420-1480 \mathrm{~cm}^{-1}$. Three absorption bands at $\sim 800 \mathrm{~cm}^{-1}$ (strongest), 850 and $880 \mathrm{~cm}^{-1}$ are related to carbonate bending vibrations. The $v_{1}$ symmetric stretching vibration appears as an absorption band at $\sim 1120 \mathrm{~cm}^{-1}$. Finally, in this region, 
HY IR spectrum shows at $\sim 1645 \mathrm{~cm}^{-1}$ a very weak absorption, which appears only as a faint shoulder, in contrast with the marked absorption of the nesquehonite [5].

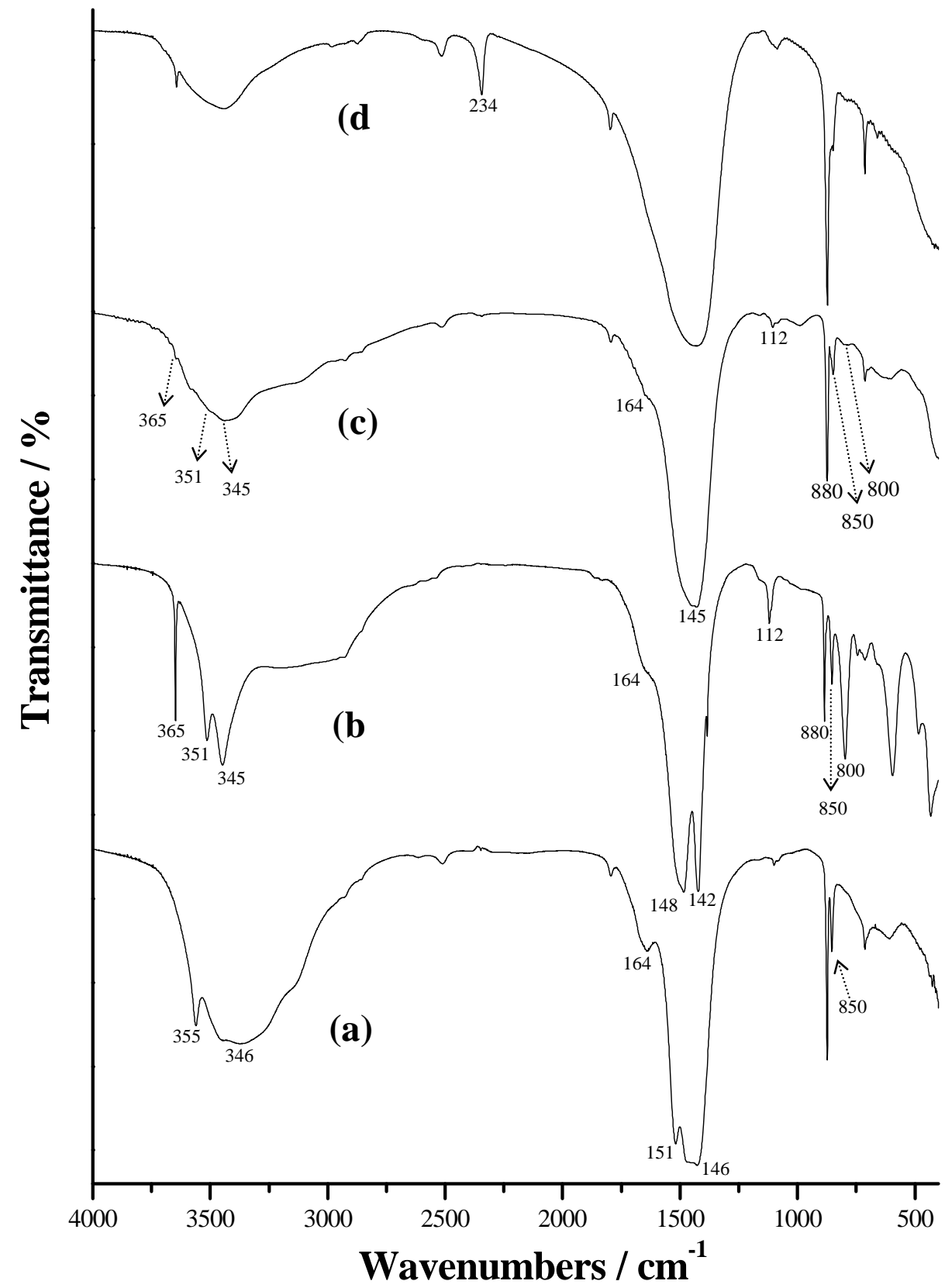

Fig. 6. FT-IR spectra. (a) Untreated sample (nesquehonite + calcite); (b) Hydromagnesite (HY); (c) Sample heated at $115^{\circ} \mathrm{C} / 18 \mathrm{~h}$ (UIC + Calcite); (d) Sample treated at $230^{\circ} \mathrm{C} / 30 \mathrm{~min}$ (amorphous compound + calcite).

In this region, the UIC shows an absorption band at $\sim 1420-1480 \mathrm{~cm}^{-1}$. This band is observed for HY split in two. As reported by Botha and Strydom [5], this band is broader and single for the UIC, which indicates the amorphous structure of the UIC. 
Absorption bands at 800,850 and $880 \mathrm{~cm}^{-1}$ can be observed, as in the HY IR spectrum. However, a marked difference is noticeable: HY shows its strongest absorption band at $800 \mathrm{~cm}^{-1}$, whereas UIC gives a very weak absorption at this wavenumber.

The UIC IR spectrum matches the HY spectrum in the aforementioned absorption bands and their intensity ratios at $\sim 1120$ and $\sim 1645 \mathrm{~cm}^{-1}$. These bands also indicate some differences with the nesquehonite IR spectrum.

As can be observed, the absorption band at $\sim 1120 \mathrm{~cm}^{-1}$ is detected for the sample heated at $115^{\circ} \mathrm{C}$ (where the UIC occurrence is proved), but it is very weak for the sample heated at $230^{\circ} \mathrm{C}$, when UIC disappears and gives a more amorphous structure. This band can be assigned to the $v_{1}$ carbonate symmetric stretching vibrations, and its lower intensity ratio could be indicative for a certain degree of decarbonation due to the lengthy thermal treatment at $230^{\circ} \mathrm{C}$.

In the region between 2000 and $4000 \mathrm{~cm}^{-1}$ the three crystal water molecules for $\mathrm{N}$ can be identified. A sharp band occurs at $3555 \mathrm{~cm}^{-1}$, and another band absorption at $3460 \mathrm{~cm}^{-1}$. These bands differ from the HY spectrum, which shows a sharp band at $\sim 3650 \mathrm{~cm}^{-1}$ (free O-H vibration correlated to the DTA-TG measured dehydration (Fig. 3)), and bands resulting from water of crystallization at $\sim 3510$ and $\sim 3450 \mathrm{~cm}^{-1}$ [5].

As can be observed from our experimental results, the UIC spectrum corresponds to a greater extent with the HY spectrum than with the $\mathrm{N}$ spectrum. Bands are observed at 3650, 3510 and $3450 \mathrm{~cm}^{-1}$. However, some differences can also be detected: the band at $3650 \mathrm{~cm}^{-1}$ is very weak, so the number of hydroxyl groups in UIC must be lower than in HY. This fact is confirmed by the absence of a relevant endothermic phenomenon in DTA-TG curves around $\sim 300^{\circ} \mathrm{C}$ (only a slightly marked minimum in DTG curve (Fig. 5)), which would correspond to dehydration as in the HY thermal decomposition (Fig. 3) $[5,7]$. 
The band between 3300 and $3500 \mathrm{~cm}^{-1}$ turns out to be broader than the HY absorption band, and this fact could indicate the occurrence of different types of water of crystallization according to the amorphous structure of UIC [5].

A difference can be seen between UIC (obtained after heating at $115^{\circ} \mathrm{C}$ ) and the next amorphous structure obtained after thermal treatment at $230^{\circ} \mathrm{C}$ : this secondary amorphous structure shows a sharp band at $2346 \mathrm{~cm}^{-1}$. This band appears in the paper by Botha and Strydom [D-25] and is the result of the dehydration of a compound very similar to UIC. The authors assign this band to either a $\mathrm{CO}_{2}$ inclusion or a terminal $\mathrm{CO}_{2}$, but they indicate that a more detailed analysis would be necessary.

These results clearly establish that UIC has a resemblance with the hydromagnesite (very close chemical composition), but it shows a poorly crystallized structure, more amorphous in nature, as XRD reveals.

Heating at higher temperatures (Fig. 4) shows the disappearance of the UIC, which can not be detected by $\mathrm{XRD}$. At $230^{\circ} \mathrm{C} / 30 \mathrm{~min}$ nesquehonite is not detected, neither UIC, and only a broad band of diffraction around $15^{\circ} 2 \theta$ reveals the presence of an amorphous phase. In Fig. 7, DTA-TG curves show a thermal decomposition very similar to that of $\mathrm{HY}$, as expected: a small endothermic peak at around $280^{\circ} \mathrm{C}$ can be attributed to the dehydration process (absorption band at $\sim 3650^{\circ} \mathrm{C} \mathrm{cm}^{-1}$ in the IR spectrum, Fig. 6). Thermogravimetric calculations for this temperature of heating also correspond with the chemical composition of HY, after taking into account in the theoretical calculation the weight loss of $\mathrm{HY}$ at this temperature of treatment (Table 1). The consecutive heating at higher temperatures $\left(>230^{\circ} \mathrm{C}\right)$ confirms these results. The nesquehonite structure disappears; it can not be detected by XRD (Fig. 4). The UIC is not detectable. 


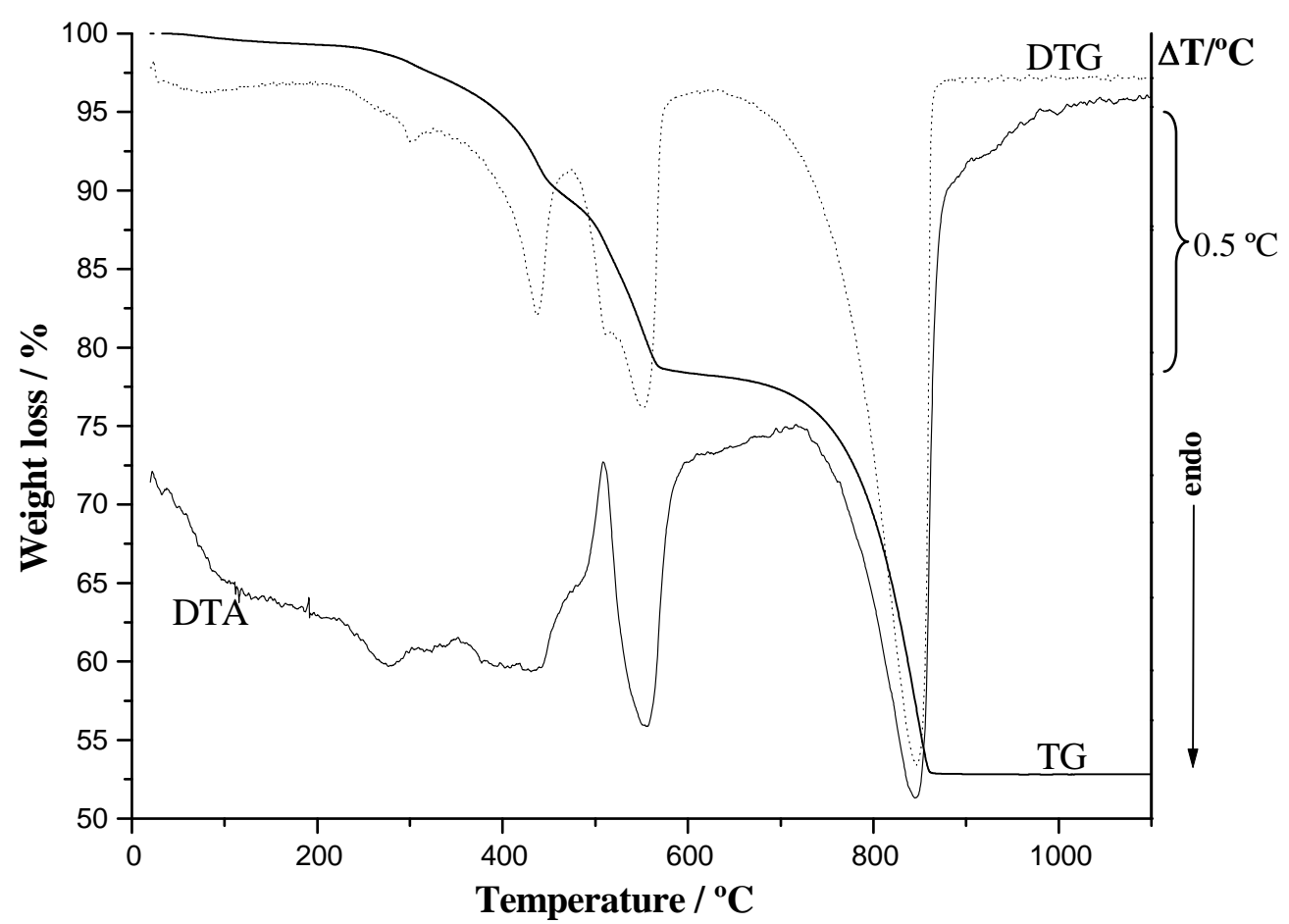

Fig. 7. TG, DTG, and DTA curves of the carbonated lime paste heated at $230^{\circ} \mathrm{C}$ during $30 \mathrm{~min}$.

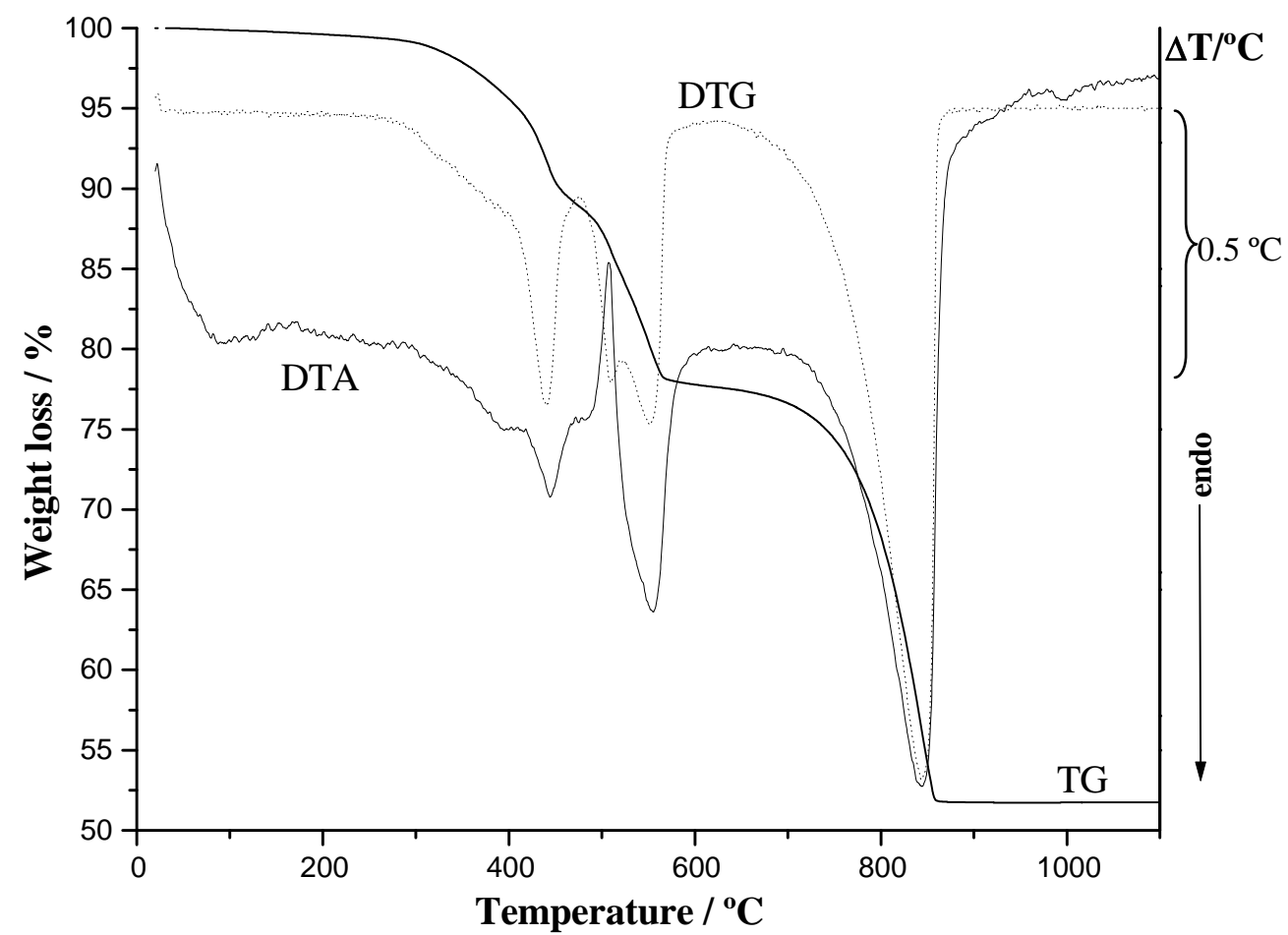

Fig. 8. TG, DTG, and DTA curves of the carbonated lime paste heated at $280^{\circ} \mathrm{C}$ during $30 \mathrm{~min}$.

DTA-TG curves show the phenomena above the temperature of heating, as expected (Fig. 8). However, some weight losses can be seen to start too soon (e.g. $280^{\circ} \mathrm{C} / 30 \mathrm{~min}$ ) and this fact can be due to the low degree of crystallinity of the product, which releases water or carbon dioxide at lower temperatures (Fig. 8). 
$\mathrm{MgO}$ can not be detected below $280^{\circ} \mathrm{C}$ by XRD. Traces of $\mathrm{MgO}$ are observed after heating at $370^{\circ} \mathrm{C} / 16 \mathrm{~h}$. These facts suggest decarbonations above $\sim 350^{\circ} \mathrm{C}$ and dehydrations below this temperature. However, the limit between these processes is not clearly established, and it is possible to observe dehydrations above $350^{\circ} \mathrm{C}$ [13].

At $460^{\circ} \mathrm{C} / 5-10$ min a marked difference with the previous results can be observed: HY appears according to XRD data together with $\mathrm{N}$ (Fig. 9). After 15 minutes of heating, $\mathrm{N}$ disappears and only HY and calcite can be detected. At 20 minutes, HY disappears, and a broad band of diffraction reveals the occurrence of an amorphous structure. The evolution of DTA curves corresponds with these observations: an increase of the heating time allows the establishment of the thermal equilibrium and it causes a gradual disappearance of the phenomena below $460^{\circ} \mathrm{C}$ (Fig. 10).

The coexistence of $\mathrm{N}$ and HY however does not give either shoulders a doublet in the DTA curves (Fig. 10 at 5-10 min). Therefore, it can be concluded that their thermal decomposition is similar.

At $520^{\circ} \mathrm{C}$, XRD does not show the occurrence of $\mathrm{N}$ at early heating times. HY and UIC have not been identified (Fig. 4). DTA curves show the gradual evolution of the thermal phenomena as a function of the heating temperature, up to disappearance of the exothermic phenomenon (Fig. 11). 


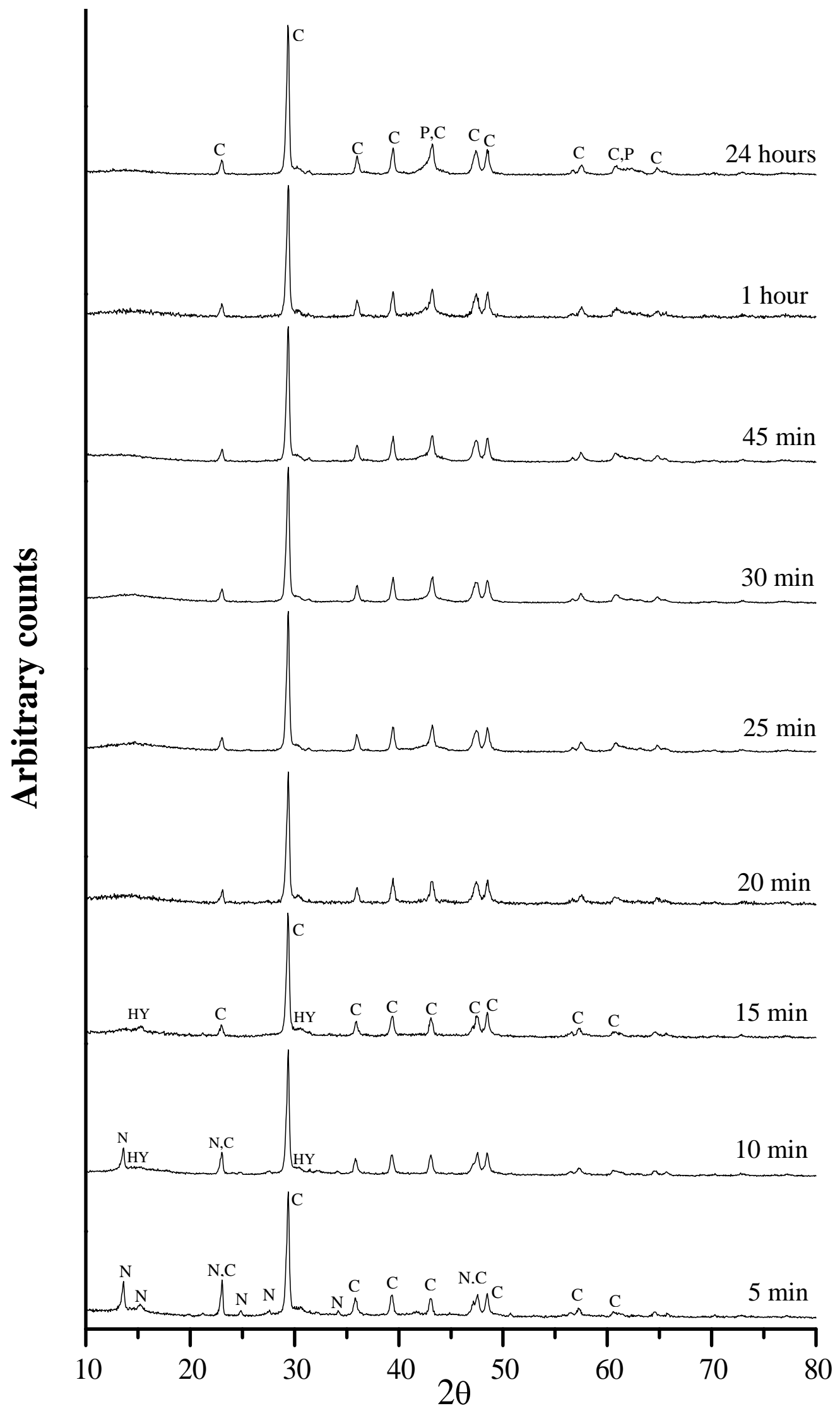

Fig. 9. XRD of the carbonated lime paste evolution heated at $460^{\circ} \mathrm{C}$ at different times. (C: Calcite $\left(\mathrm{CaCO}_{3}\right)$ (ICDD 05-0586); HY: Hydromagnesite $\left(\mathrm{Mg}_{5}\left(\mathrm{CO}_{3}\right)_{4}(\mathrm{OH})_{2} \cdot 4 \mathrm{H}_{2} \mathrm{O}\right)$ (ICDD 70-1177); N: Nesquehonite $\left(\mathrm{MgCO}_{3} \cdot 3 \mathrm{H}_{2} \mathrm{O}\right)$ (ICDD 20-0669)). 


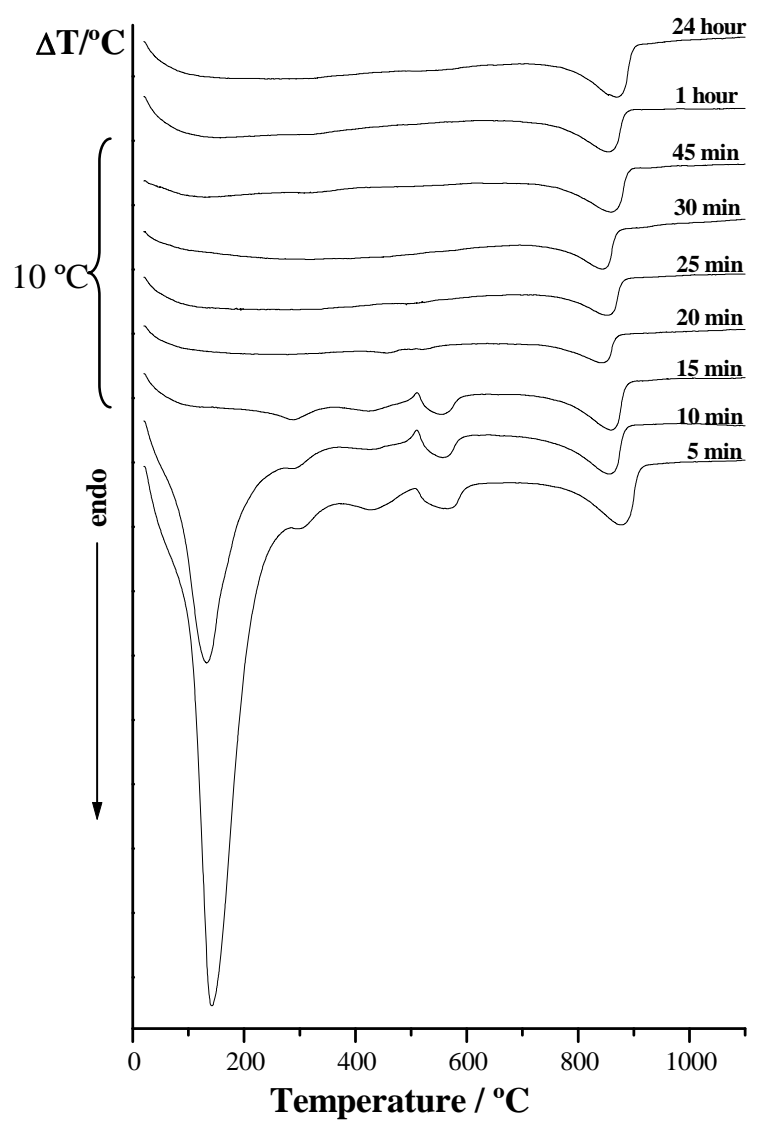

Fig. 10. DTA curves of dolomitic lime paste heated at $460^{\circ} \mathrm{C}$ at different times.

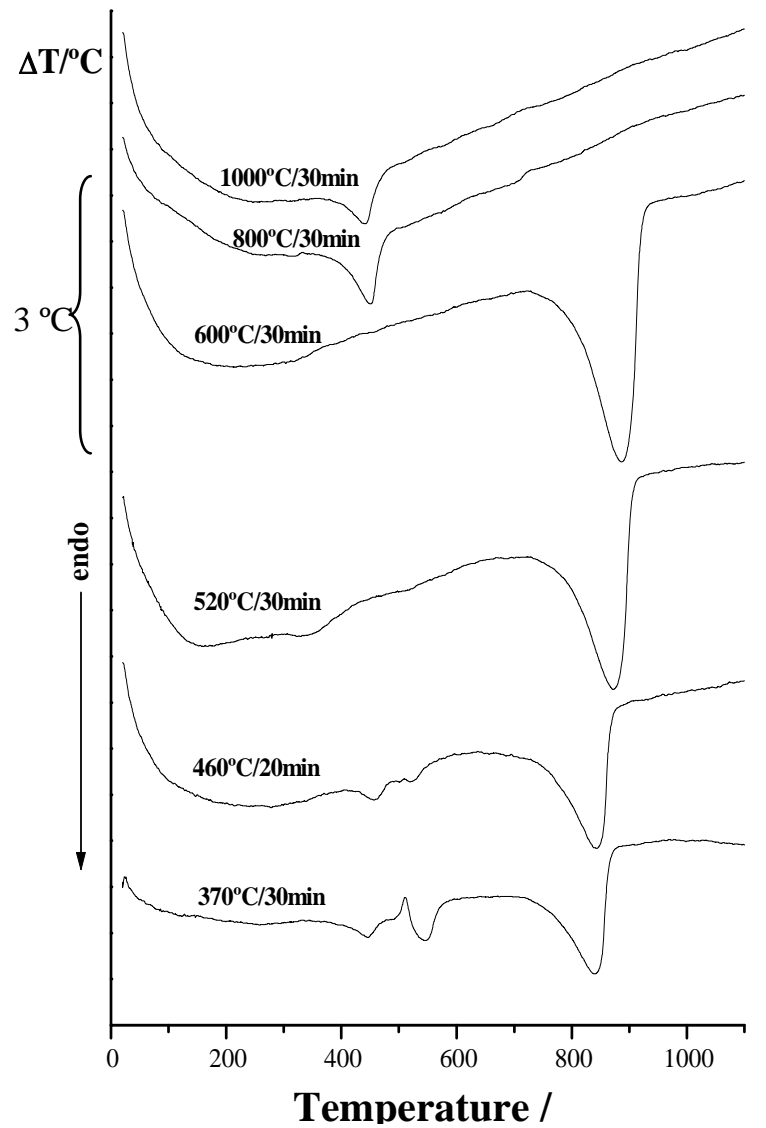

Fig. 11. DTA curves of carbonated lime paste heated at different temperatures. 
The influence of procedural variables in the occurrence of the exothermic phenomenon has been mentioned before [11,13]. As reported in our previous work [11], a selfgenerated atmosphere contributes to the detection of this peak. The holed lids used, the heating rate, the atmosphere and a packed sample are critical to observe the phenomenon. Fig. 12 reflects DTA curves for the original untreated sample in the aforementioned conditions of this study (curve A), and crucibles without lid in static air atmosphere (curve $\mathrm{B}$ ) and without lid in a dynamic $\mathrm{CO}_{2}$ flow of $150 \mathrm{~mL} \cdot \mathrm{min}^{-1}$ (curve C).

As expected, the exothermic phenomenon is poorly detectable in curve B. In curve C the phenomenon is clearly seen, but with a shift towards higher temperatures for the decarbonation peaks.

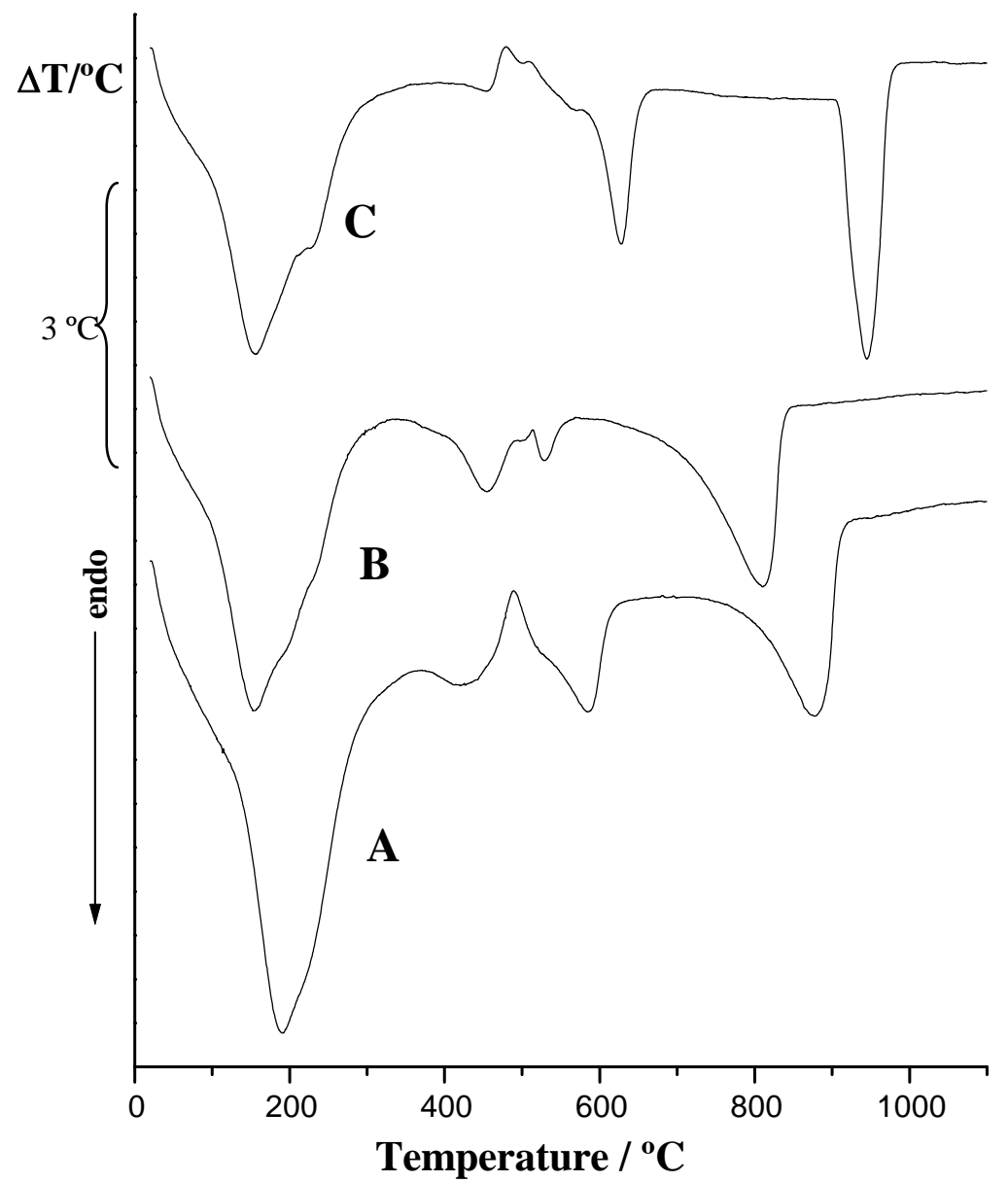

Fig. 12. DTA curves of carbonated lime paste measurement at different conditions: (A) crucible with lid in static air atmosphere; (B) crucible without lid temperature in static air atmosphere; (C) crucible without lid in a dynamic $\mathrm{CO}_{2}$ flow $\left(150 \mathrm{~mL} \cdot \mathrm{min}^{-1}\right)$. 
Higher heating temperatures show the expected behavior (Figs. 4 and 11), with the absence of the aforementioned thermal phenomena.

\subsection{Discussion}

From the present results, it can conclude that nesquehonite transforms at lower temperatures $\left(115^{\circ} \mathrm{C}\right)$ into a stable and amorphous magnesium carbonate (UIC), with a chemical composition very close to that of $\mathrm{HY}$. At $460^{\circ} \mathrm{C}$ this UIC is not formed, and $\mathrm{N}$ transforms into HY, which gives a different amorphous structure at longer heating times.

The UIC matches with that reported by Botha and Strydom [4]. These authors find that UIC does not transform into $\mathrm{HY}$, as expected, and state that an alternative mechanism possibly existed by which nesquehonite is converted to HY.

From our results, this UIC does not transform into HY and thermal decomposition of N, during gradual temperature increases, proceeds via the UIC formation. Nevertheless, HY can be obtained by a forced heating of the nesquehonite at higher temperatures $\left(>>115^{\circ} \mathrm{C}\right)$, such as heating at $460^{\circ} \mathrm{C} / 5-10$ minutes. However, the $\mathrm{HY}$ formation at $230^{\circ}, 280^{\circ}$ and $370^{\circ} \mathrm{C}$ at early heating times cannot be totally dismissed. It is possible that the involved mechanism in the heating conditions will be different and the HY formation would be favored.

In contrast to the HY thermal decomposition, reported by Sawada and co-workers $[6,14], \mathrm{N}$ losses its crystalline structure and transforms into the amorphous UIC at lower temperatures $\left(115^{\circ} \mathrm{C}\right)$. However, HY keeps its structure up to $\sim 300^{\circ} \mathrm{C}$. Above this temperature, HY gives an amorphous diffraction pattern.

This different thermal stability indicates the different structural stabilities, that is lower for $\mathrm{N}$ than for $\mathrm{HY}$, and it could be due to the higher water content in $\mathrm{N}$. This produces a 
more unstable structure, as can be seen from the transformation of $\mathrm{N}$ into UIC when water is lost.

\section{Conclusions}

1. During gradual heating, thermal decomposition of nesquehonite proceeds via an unidentified product (UIC) with a chemical composition very close to hydromagnesite.

This basic magnesium carbonate shows an amorphous diffraction pattern, and corresponds to that reported by Botha and Strydom.

2. Thermal decomposition of nesquehonite coincides exactly with that of HY, above of $350^{\circ} \mathrm{C}$.

The occurrence of the exothermic phenomenon at $510^{\circ} \mathrm{C}$, as well as the fact that HY decomposition is influenced by the procedural variables e.g. the obtaining of a self-generated atmosphere allows one to check the phenomenon.

3. Nesquehonite transforms into HY by heating the pastes for short times at higher temperatures $\left(>>115^{\circ} \mathrm{C}\right)$. Later, when increasing the heating time, $\mathrm{HY}$ transforms into an amorphous structure with similar thermal behavior than the HY.

\section{Acknowledgements}

The present study was supported by the Spanish Ministerio de Ciencia y Tecnología, Plan Nacional de Investigación, Desarrollo e Innovación Tecnológica (I+D+I) program, Project MAT 2000-1347.

The authors would like to thank D. José Luis Liendo (Dolimitas del Norte - Calcinor, Santullán, Cantabria) for the material supplied. We are also grateful to Iñigo X. GarcíaZubiri for help with the IR interpretations. 


\section{References}

[1] J. Lanas, J.I. Alvarez, submitted for publication at Thermochim. Acta.

[2] P.J. Davies and B. Bubela, Chemical Geology, 12 (1973) 289-300.

[3] E. Königsberger, L.-C. Königsberger and H. Gamsjäger, Geochim. Cosmochim. Acta 63 (19/20) (1999) 3105-3119.

[4] A. Botha and C.A. Strydom, Hydrometallurgy 62 (2001) 175-183.

[5] A. Botha and C.A. Strydom, J. Therm. Anal. Cal., 71 (2003) 987-995.

[6] Y. Sawada, K. Uematsu, N. Mizutani and M. Kato, Thermochim. Acta 27 (1978) 4559.

[7] Y. Sawada, K. Uematsu, N. Mizutani and M. Kato, Thermochim. Acta 32 (1979) 277-291.

[8] T.L. Webb, J.E., Krüger, Carbonates, in: R.C. McKenzie (Ed.), Differential Thermal Analysis, Academic Press, London, 1970, pp. 238-266.

[9] J.T. Kloprogge, W.N. Martens, L. Nothdurft, L.V. Duong, G.E. Webb, J. Mater. Sci. Lett. 22 (2003) 825-829.

[10] Brousse, R. and Guerin H., Bull. Soc. France Min. Crist., 89 (1966) 281-282.

[11] C. Montoya, J. Lanas, M. Arandigoyen, I. Navarro, P.J. García Casado, J. I. Alvarez, Thermochim. Acta 398 (2003) 107-122.

[12] E.E. Coleyshaw, G. Crump, W.P. Griffith, Spectrochimica Acta Part A 59 (2003) 2231-2239.

[13] N. Khan, D. Dollimore, K. Alexander, F.W. Wilburn, Thermochim. Acta 367-368 (2001) 321-333.

[14] Y. Sawada, J. Yamaguchi, O. Sakurai, K. Uematsu, N. Mizutani, M. Kato, Thermochim. Acta 33 (1979) 127-140. 